4

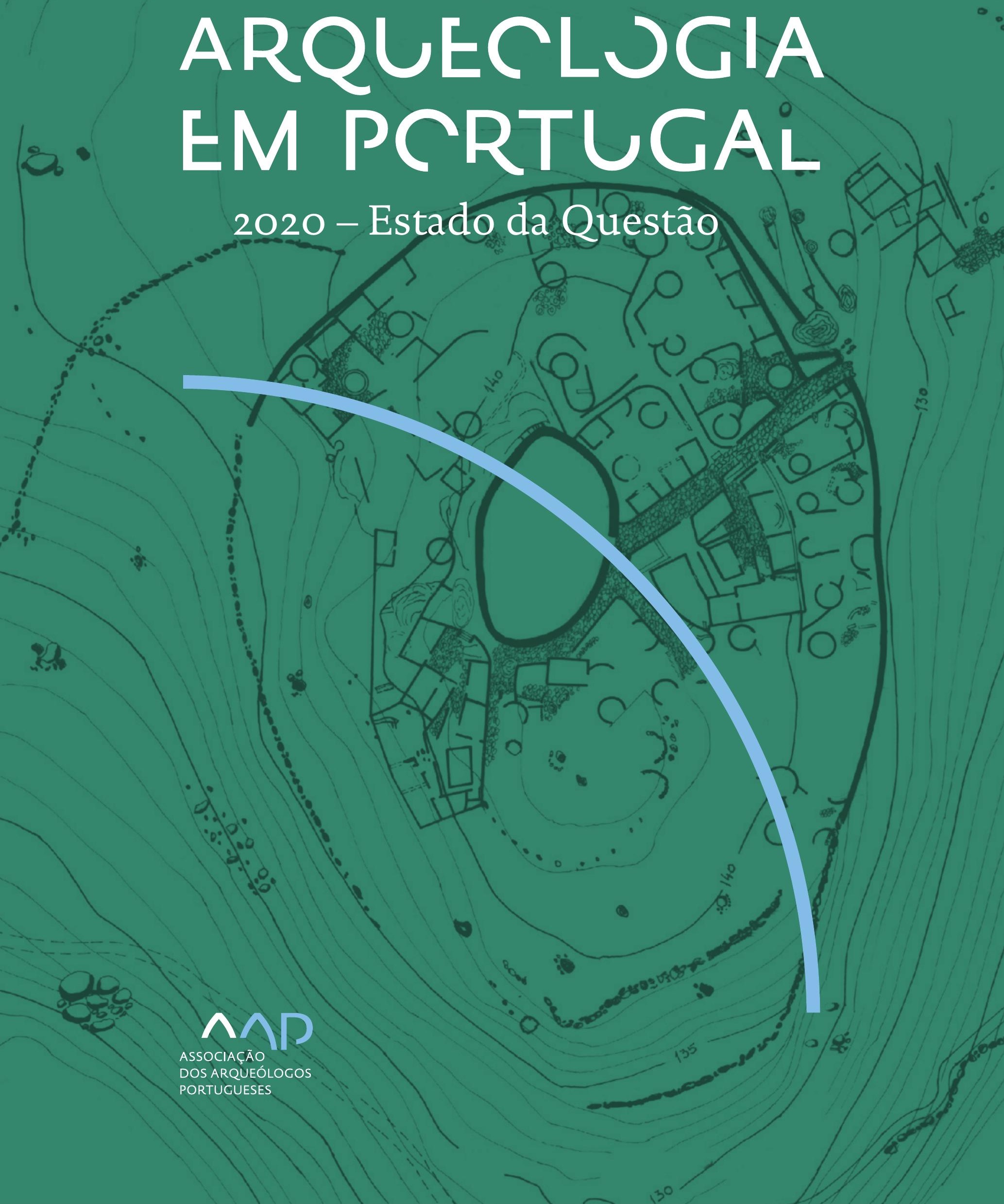


Coordenação editorial: José Morais Arnaud, César Neves e Andrea Martins Design gráfico: Flatland Design

AAP - ISBN: 978-972-9451-89-8

CITCEM - ISBN: 978-989-8970-25-1

Associação dos Arqueólogos Portugueses e CITCEM

Lisboa, 2020

O conteúdo dos artigos é da inteira responsabilidade dos autores. Sendo assim a Associação dos Arqueólogos Portugueses declina qualquer responsabilidade por eventuais equívocos ou questões de ordem ética e legal.

Desenho de capa:

Planta do castro de Monte Mozinho (Museu Municipal de Penafiel).

\section{$\hat{\wedge} \mathrm{P}$}

DOS ARQUEÓLOGOS PORTUGUESES

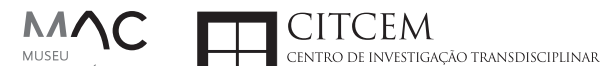
MUSEU
ARQUELLÓGICO
DO CARMO
U.PORTO

FLUP FACULDADE DE LETRAS
UNIVERSIDADE DO PORTO

Apoio

EC para a Ciência 


\section{Índice}

15 Prefácio

José Morais Arnaud

\section{Historiografia e Teoria}

17 Território, comunidade, memória e emoção: a contribuição da história da arqueologia (algumas primeiras e breves reflexões)

Ana Cristina Martins

25 Como descolonizar a arqueologia portuguesa?

Rui Gomes Coelho

41 Arqueologia e Modernidade: uma revisitação pessoal e breve de alguns aspetos da obra homónima de Julian Thomas de 2004

Vítor Oliveira Jorge

57 Dados para a História das Mulheres na Arqueologia portuguesa, dos finais do século XIX aos inícios do século XX: números, nomes e tabelas

Filipa Dimas / Mariana Diniz

73 Retractos da arqueologia portuguesa na imprensa: (in)visibilidades no feminino

Catarina Costeira / Elsa Luís

85 Arqueologia e Arqueólogos no Norte de Portugal Jacinta Bugalhão

101 Vieira Guimarães (1864-1939) e a arqueologia em Tomar: uma abordagem sobre o território e as gentes

João Amendoeira Peixoto / Ana Cristina Martins

115 Os memoráveis? A arqueologia algarvia na imprensa nacional e regional na presente centúria (2001-2019): características, visões do(s) passado(s) e a arqueologia

enquanto marca

Frederico Agosto / João Silva

129 A Evolução da Arqueologia Urbana e a Valorização Patrimonial no Barlavento Algarvio: Os casos de Portimão e Silves

Artur Mateus / Diogo Varandas / Rafael Boavida

\section{Gestão, Valorização e Salvaguarda do Património}

145 O Caderno Reivindicativo e as condições de trabalho em Arqueologia Miguel Rocha / Liliana Matias Carvalho / Regis Barbosa / Mauro Correia / Sara Simões / Jacinta Bugalhão / Sara Brito / Liliana Veríssimo Carvalho / Richard Peace / Pedro Peça / Cézer Santos

155 Os Estudos de Impacte Patrimonial como elemento para uma estratégia sustentável de minimização de impactes no âmbito de reconversões agrícolas Tiago do Pereiro

165 Salvaguarda de Património arqueológico em operações florestais: gestão e sensibilização Filipa Bragança / Gertrudes Zambujo / Sandra Lourenço / Belém Paiva / Carlos Banha / Frederico Tatá Regala / Helena Moura / Jacinta Bugalhão / João Marques / José Correia / Pedro Faria / Samuel Melro

179 Os valores do Património: uma investigação sobre os Sítios Pré-históricos de Arte Rupestre do Vale do Rio Côa e de Siega Verde José Paulo Francisco 
189 Conjugando recursos arqueológicos e naturais para potenciar as visitas ao Geoparque Litoral de Viana do Castelo (Noroeste de Portugal)

Hugo A. Sampaio / Ana M.S. Bettencourt / Susana Marinho / Ricardo Carvalhido

203 Áreas de Potencial Arqueológico na Região do Médio Tejo: Modelo Espacial Preditivo Rita Ferreira Anastácio / Ana Filipa Martins / Luiz Oosterbeek

223 Património Arqueológico e Gestão Territorial: O contributo da Arqueologia para a revisão do PDM de Avis

Ana Cristina Ribeiro

237 A coleção arqueológica do extinto Museu Municipal do Porto - Origens, Percursos e Estudos

Sónia Couto

251 Valpaços - uma nova carta arqueológica

Pedro Pereira / Maria de Fátima Casares Machado

263 Arqueologia na Cidade de Peniche

Adriano Constantino / Luís Rendeiro

273 Arqueologia Urbana: a cidade de Lagos como caso de Estudo Cátia Neto

285 Estratégias de promoção do património cultural subaquático nos Açores. O caso da ilha do Faial

José Luís Neto / José Bettencourt / Luís Borges / Pedro Parreira

297 Carta Arqueológica da Cidade Velha: Uma primeira abordagem

Jaylson Monteiro / Nireide Tavares / Sara da Veiga / Claudino Ramos / Edson Brito /

Carlos Carvalho / Francisco Moreira / Adalberto Tavares

311 Antropologia Virtual: novas metodologias para a análise morfológica e funcional Ricardo Miguel Godinho / Célia Gonçalves

\section{Didáctica da Arqueologia}

327 Como os projetos de Arqueologia podem contribuir para uma comunidade culturalmente mais consciente Alexandra Figueiredo / Claúdio Monteiro / Adolfo Silveira / Ricardo Lopes

337 Educação Patrimonial - Um cidadão esclarecido é um cidadão ativo! Ana Paula Almeida

351 A aproximação da Arqueologia à sala de aula: um caso de estudo no $3^{\circ}$ ciclo do Ensino Básico Luís Serrão Gil

363 Arqueologia 3.o - Pensar e comunicar a Arqueologia para um futuro sustentável Mónica Rolo

377 “Conversa de Arqueólogos" - Divulgar a Arqueologia em tempos de Pandemia Diogo Teixeira Dias

389 Escola Profissional de Arqueologia: desafios e oportunidades Susana Nunes / Dulcineia Pinto / Júlia Silva / Ana Mascarenhas

399 Os Museus de Arqueologia e os Jovens: a oferta educativa para o público adolescente Beatriz Correia Barata / Leonor Medeiros

411 O museu universitário como mediador entre a ciência e a sociedade: o exemplo da secção de arqueologia no Museu de História Natural e da Ciência da Universidade do Porto (MHNC-UP)

Rita Gaspar 
421 Museu de Lanifícios: Real Fábrica de Panos. Atividades no âmbito da Arqueologia Beatriz Correia Barata / Rita Salvado

427 Arqueologia Pública e o caso da localidade da Mata (Torres Novas) Cláudia Manso / Ana Rita Ferreira / Cristiana Ferreira / Vanessa Cardoso Antunes

431 Do sítio arqueológico ao museu: um percurso (também) didático Lídia Fernandes

447 Estão todos convidados para a Festa! E para dançar também... O projecto do Serviço Educativo do Museu Arqueológico do Carmo na $5^{\underline{a}}$ Edição da Festa da Arqueologia Rita Pires dos Santos

459 O “Clã de Carenque”, um projeto didático de arqueologia Eduardo Gonzalez Rocha

469 Mediação cultural: peixe que puxa carroça nas Ruínas Romanas de Troia Inês Vaz Pinto / Ana Patrícia Magalhães / Patrícia Brum / Filipa Santos

481 Didática Arqueológica, experiências do Projeto Mértola Vila Museu Maria de Fátima Palma / Clara Rodrigues / Susana Gómez / Lígia Rafael

\section{Arte Rupestre}

497 Os inventários de arte rupestre em Portugal Mila Simões de Abreu

513 O projeto FIRST-ART - conservação, documentação e gestão das primeiras manifestações de arte rupestre no Sudoeste da Península Ibérica: as grutas do Escoural e Maltravieso Sara Garcês / Hipólito Collado / José Julio García Arranz / Luiz Oosterbeek / António Carlos Silva / Pierluigi Rosina / Hugo Gomes / Anabela Borralheiro Pereira / George Nash / Esmeralda Gomes / Nelson Almeida / Carlos Carpetudo

523 Trabalhos de documentação de arte paleolítica realizados no âmbito do projeto PalæoCôa André Tomás Santos / António Fernando Barbosa / Luís Luís / Marcelo Silvestre / Thierry Aubry

537 Imagens fantasmagóricas, silhuetas elusivas: as figuras humanas na arte do Paleolítico Superior da região do Côa Mário Reis

$55^{1}$ Os motivos zoomórficos representados nas placas de tear de Vila Nova de São Pedro (Azambuja, Portugal) Andrea Martins / César Neves / José M. Arnaud / Mariana Diniz

571 Arte Rupestre do Monte de Góios (Lanhelas, Caminha). Síntese dos resultados dos trabalhos efectuados em 2007-2009 Mário Varela Gomes

599 Gravuras rupestres de barquiformes no Monte de S. Romão, Guimarães, Noroeste de Portugal Daniela Cardoso

613 Círculos segmentados gravados na Bacia do Rio Lima (Noroeste de Portugal): contributos para o seu estudo Diogo Marinho / Ana M.S. Bettencourt / Hugo Aluai Sampaio

631 Equídeos gravados no curso inferior do Rio Mouro, Monção (NW Portugal). Análise preliminar Coutinho, L.M. / Bettencourt, A.M.S / Sampaio, Hugo A.S

645 Paletas na Arte Rupestre do Noroeste de Portugal. Inventário preliminar Bruna Sousa Afonso / Ana M. S. Bettencourt / Hugo A. Sampaio 


\section{Pré-História}

661 O projeto Miño/Minho: balanço de quatro anos de trabalhos arqueológicos Sérgio Monteiro-Rodrigues / João Pedro Cunha-Ribeiro / Eduardo Méndez-Quintas / Carlos Ferreira / Pedro Xavier / José Meireles / Alberto Gomes / Manuel Santonja / Alfredo Pérez-González

677 A ocupação paleolítica da margem esquerda do Baixo Minho: a indústria lítica do sítio de Pedreiras 2 (Monção, Portugal) e a sua integração no contexto regional Carlos Ferreira / João Pedro Cunha-Ribeiro / Sérgio Monteiro-Rodrigues / Eduardo Méndez-Quintas / Pedro Xavier / José Meireles / Alberto Gomes / Manuel Santonja / Alfredo Pérez-González

693 O sítio acheulense do Plistocénico médio da Gruta da Aroeira Joan Daura / Montserrat Sanz / Filipa Rodrigues / Pedro Souto / João Zilhão

703 As sociedades neandertais no Barlavento algarvio: modelos preditivos com recurso aos SIG

Daniela Maio

715 A utilização de quartzo durante o Paleolítico Superior no território dos vales dos rios Vouga e Côa

Cristina Gameiro / Thierry Aubry / Bárbara Costa / Sérgio Gomes / Luís Luís / Carmen Manzano / André Tomás Santos

733 Uma perspetiva diacrónica da ocupação do concheiro do Cabeço da Amoreira (Muge, Portugal) a partir da tecnologia lítica Joana Belmiro / João Cascalheira / Célia Gonçalves

745 Novos dados sobre a Pré-história Antiga no concelho de Palmela. A intervenção arqueológica no sítio do Poceirão I

Michelle Teixeira Santos

757 Problemas em torno de Datas Absolutas Pré-Históricas no Norte do Alentejo Jorge de Oliveira

771 Povoamento pré-histórico nas áreas montanhosas do NO de Portugal: o Abrigo 1 de Vale de Cerdeira Pedro Xavier / José Meireles / Carlos Alves

783 Apreciação do povoamento do Neolítico Inicial na Baixa Bacia do Douro. A Lavra I (Serra da Aboboreira) como caso de estudo Maria de Jesus Sanches

797 O Processo de Neolitização na Plataforma do Mondego: os dados do Sector C do Outeiro dos Castelos de Beijós (Carregal do Sal)

João Carlos de Senna-Martinez / José Manuel Quintã Ventura / Andreia Carvalho / Cíntia Maurício

823 Novos trabalhos na Lapa da Bugalheira (Almonda, Torres Novas) Filipa Rodrigues / Pedro Souto / Artur Ferreira / Alexandre Varanda / Luís Gomes / Helena Gomes / João Zilhão

837 A pedra polida e afeiçoada do sítio do Neolítico médio da Moita do Ourives (Benavente, Portugal)

César Neves

857 Casal do Outeiro (Encarnação, Mafra): novos contributos para o conhecimento do povoamento do Neolítico final na Península de Lisboa.

Cátia Delicado / Carlos Maneira e Costa / Marta Miranda / Ana Catarina Sousa

873 Stresse infantil, morbilidade e mortalidade no sítio arqueológico do Neolítico Final/ Calcolítico ( $4^{\circ}$ e $3^{\circ}$ milénio a.C.) do Monte do Carrascal 2 (Ferreira do Alentejo, Beja) Liliana Matias de Carvalho / Sofia N. Wasterlain 
885 Come together: O Conjunto Megalítico das Motas (Monção, Viana do Castelo) e as expressões Campaniformes do Alto Minho Ana Catarina Basílio / Rui Ramos

899 Trabalhos arqueológicos no sítio Calcolítico da Pedreira do Poio Carla Magalhães / João Muralha / Mário Reis / António Batarda Fernandes

913 O sítio arqueológico de Castanheiro do Vento. Da arquitectura do sítio à arquitectura de um território João Muralha Cardoso

925 Estudo zooarqueológico das faunas do Calcolítico final de Vila Nova de São Pedro (Azambuja, Portugal): Campanhas de 2017 e 2018 Cleia Detry / Ana Catarina Francisco / Mariana Diniz / Andrea Martins / César Neves / José Morais Arnaud

943 As faunas depositadas no Museu Arqueológico do Carmo provenientes de Vila Nova de São Pedro (Azambuja): as campanhas de 1937 a 1967 Ana Catarina Francisco / Cleia Detry / César Neves / Andrea Martins / Mariana Diniz / José Morais Arnaud

959 Análise funcional de material lítico em sílex do castro de Vila Nova de S. Pedro (Azambuja, Portugal): uma primeira abordagem Rafael Lima

971 O recinto da Folha do Ouro 1 (Serpa) no contexto dos recintos de fossos calcolíticos alentejanos

António Carlos Valera / Tiago do Pereiro / Pedro Valério / António M. Monge Soares

\section{Proto-História}

987 Produção de sal marinho na Idade do Bronze do noroeste Português. Alguns dados para uma reflexão

Ana M. S. Bettencourt / Sara Luz / Nuno Oliveira / Pedro P. Simões / Maria Isabel C. Alves / Emílio Abad-Vidal

1001 A estátua-menir do Pedrão ou de São Bartolomeu do Mar (Esposende, noroeste de Portugal) no contexto arqueológico da fachada costeira de entre os rios Neiva e Cávado Ana M. S. Bettencourt / Manuel Santos-Estévez / Pedro Pimenta Simões / Luís Gonçalves

1015 O Castro do Muro (Vandoma/Baltar, Paredes) - notas para uma biografia de ocupação da Idade do Bronze à Idade Média

Maria Antónia D. Silva / Ana M. S. Bettencourt / António Manuel S. P. Silva / Natália Félix

1031 Do Bronze Final à Idade Média - continuidades e hiatos na ocupação de Povoados em Oliveira de Azeméis João Tiago Tavares / Adriaan de Man

1041 As faunas do final da Idade do Bronze no Sul de Portugal: leituras desde o Outeiro do Circo (Beja)

Nelson J. Almeida / Íris Dias / Cleia Detry / Eduardo Porfírio / Miguel Serra

1055 A Espada do Monte das Oliveiras (Serpa) - uma arma do Bronze Pleno do Sudoeste Rui M. G. Monge Soares / Pedro Valério / Mariana Nabais / António M. Monge Soares

1065 São Julião da Branca (Albergaria-a-Velha) - Investigação e valorização de um povoado do Bronze Final

António Manuel S. P. Silva / Paulo A. P. Lemos / Sara Almeida e Silva / Edite Martins de Sá

1083 Do castro de S. João ao Mosteiro de Santa Clara: notícia de uma intervenção arqueológica, em Vila do Conde Rui Pinheiro 
1095 O castro de Ovil (Espinho), um quarto de século de investigação - resultados e questões em aberto

Jorge Fernando Salvador / António Manuel S. P. Silva

1111 O Castro de Salreu (Estarreja), um povoado proto-histórico no litoral do Entre Douro e Vouga

Sara Almeida e Silva / António Manuel S. P. Silva / Paulo A. P. Lemos / Edite Martins de Sá

1127 Castro de Nossa Senhora das Necessidades (Sernancelhe): uma primeira análise artefactual Telma Susana O. Ribeiro

${ }_{1141}$ A cividade de Bagunte. O estado atual da investigação Pedro Brochado de Almeida

1153 Zoomorfos na cerâmica da Idade do Ferro no NW Peninsular: inventário, cronologias e significado Nuno Oliveira / Cristina Seoane

1163 Vasos gregos em Portugal: diferentes maneiras de contar a história do intercâmbio cultural na Idade do Ferro

Daniela Ferreira

1175 Os exotica da necrópole da Idade do Ferro do Olival do Senhor dos Mártires (Alcácer do Sal) no seu contexto regional

Francisco B. Gomes

\section{Antiguidade Clássica e Tardia}

1191 O uso de madeira como combustível no sítio da Quinta de Crestelos (Baixo Sabor): da Idade do Ferro à Romanização Filipe Vaz / João Tereso / Sérgio Simões Pereira / José Sastre / Javier Larrazabal Galarza / Susana Cosme / José António Pereira / Israel Espi

1207 Cultivos de Época Romana no Baixo Sabor: continuidade em tempos de mudança? João Pedro Tereso / Sérgio Simões Pereira / Filipe Santos / Luís Seabra / Filipe Vaz

1221 A casa romana na Hispânia: aplicação dos modelos itálicos nas províncias ibéricas Fernanda Magalhães / Diego Machado / Manuela Martins

1235 As pinturas murais romanas da Rua General Sousa Machado, n. ${ }^{5}$ 1, Chaves José Carvalho

1243 Trás do Castelo (Vale de Mir, Pegarinhos, Alijó) - Uma exploração agrícola romana do Douro

Tony Silvino / Pedro Pereira

1255 A sequência de ocupação no quadrante sudeste de Bracara Augusta: as transformações de uma unidade doméstica Lara Fernandes / Manuela Martins

1263 Os Mosaicos com decoração geométrica e geométrico-vegetalista dos sítios arqueológicos da área do Conuentus Bracaraugustanus. Novas abordagens quanto à conservação, restauro, decoração e datação Maria de Fátima Abraços / Licínia Wrench

1277 “Casa Romana” do Castro de São Domingos (Cristelos, Lousada): Escavação, Estudo e Musealização Paulo André de P. Lemos

1291 A arqueobotânica no Castro de Guifões (Matosinhos, Noroeste de Portugal): O primeiro estudo carpológico

Luís Seabra / Andreia Arezes / Catarina Magalhães / José Varela / João Pedro Tereso 
1305 Um Horreum Augustano na Foz do Douro (Monte do Castelo de Gaia, Vila Nova de Gaia) Rui Ramos

1311 Ponderais romanos na Lusitânia: padrões, formas, materiais e contextos de utilização Diego Barrios Rodríguez

1323 Um almofariz centro-itálico na foz do Mondego

Marco Penajoia

1335 Estruturas romanas de Carnide - Lisboa Luísa Batalha / Mário Monteiro / Guilherme Cardoso

1347 O contexto funerário do sector da "necrópole NO" da Rua das Portas de S. Antão (Lisboa): o espaço, os artefactos, os indivíduos e a sua interconectividade na interpretação do passado Sílvia Loja, José Carlos Quaresma, Nelson Cabaço, Marina Lourenço, Sílvia Casimiro, Rodrigo Banha da Silva, Francisca Alves-Cardoso

${ }_{1361}$ Povoamento em época Romana na Amadora - resultados de um projeto pluridisciplinar Gisela Encarnação / Vanessa Dias

1371 A Arquitectura Residencial em Mirobriga (Santiago do Cacém): contributo a partir de um estudo de caso Filipe Sousa / Catarina Felício

${ }_{1385}$ O fim do ciclo. Saneamento e gestão de resíduos nos edifícios termais de Mirobriga (Santiago do Cacém)

Catarina Felício / Filipe Sousa

1399 Balsa, Topografia e Urbanismo de uma Cidade Portuária Vítor Silva Dias / João Pedro Bernardes / Celso Candeias / Cristina Tété Garcia

1413 No Largo das Mouras Velhas em Faro (2017): novas evidências da necrópole norte de Ossonoba e da sua ocupação medieval Ricardo Costeira da Silva / Paulo Botelho / Fernando Santos / Liliana Nunes

1429 Instrumentos de pesca recuperados numa fábrica de salga em Ossonoba (Faro) Inês Rasteiro / Ricardo Costeira da Silva / Paulo Botelho

1439 A Necrópole Romana do Eirô, Duas Igrejas (Penafiel): intervenção arqueológica de 2016 Laura Sousa / Teresa Soeiro

1457 Ritual, descarte ou afetividade? A presença de Canis lupus familiaris na Necrópole Noroeste de Olisipo (Lisboa)

Beatriz Calapez Santos / Sofia Simões Pereira / Rodrigo Banha da Silva / Sílvia Casimiro / Cleia Detry / Francisca Alves Cardoso

1467 Dinâmicas económicas em Bracara na Antiguidade Tardia Diego Machado / Manuela Martins / Fernanda Magalhães / Natália Botica

1479 Cerâmicas e Vidros da Antiguidade Tardia do Edifício sob a Igreja do Bom Jesus (Vila Nova de Gaia) Joaquim Filipe Ramos

1493 Novos contributos para a topografia histórica de Mértola no período romano e na Antiguidade Tardia Virgílio Lopes

\section{8. Época Medieval}

1511 Cerâmicas islâmicas no Garb setentrional "português": algumas evidências e incógnitas Constança dos Santos / Helena Catarino / Susana Gómez / Maria José Gonçalves / Isabel Inácio / Gonçalo Lopes / Jacinta Bugalhão / Sandra Cavaco / Jaquelina Covaneiro / Isabel Cristina Fernandes / Ana Sofia Gomes 
1525 Contributo para o conhecimento da cosmética islâmica, em Silves, durante a Idade Média Rosa Varela Gomes

1537 Yábura e o seu território - uma análise histórico-arqueológica de Évora entre os séculos VIII-XII José Rui Santos

1547 A encosta sul do Castelo de Palmela - resultados preliminares da escavação arqueológica Luís Filipe Pereira / Michelle Teixeira Santos

1559 A igreja de São Lourenço (Mouraria, Lisboa): um conjunto de silos e de cerâmica medieval islâmica

Andreia Filipa Moreira Rodrigues

1571 O registo material de movimentações populacionais no Médio Tejo, durante os séculos XII-XIII. Dois casos de "sunken featured buildings", nos concelhos de Cartaxo e Torres Novas Marco Liberato / Helena Santos / Nuno Santos

1585 O nordeste transmontano nos alvores da Idade média. Notas para reflexão Ana Maria da Costa Oliveira

1601 Sepulturas escavadas na rocha do Norte de Portugal e do Vale do Douro: primeiros resultados do Projecto SER-NPVD

Mário Jorge Barroca / César Guedes / Andreia Arezes / Ana Maria Oliveira

1619 "Portucalem Castrum Novum" entre o Mediterrâneo e o Atlântico: o estudo dos materiais cerâmicos alto-medievais do arqueossítio da rua de D. Hugo, nํ. 5 (Porto) João Luís Veloso

1627 A Alta Idade Média na fronteira de Lafões: notas preliminares sobre a Arqueologia no Concelho de Vouzela

Manuel Luís Real / Catarina Tente

1641 Um conjunto cerâmico medieval fora de portas: um breve testemunho aveirense Susana Temudo

${ }_{1651}$ Os Lóios do Porto: uma perspetiva integrada no panorama funerário da Baixa Idade Média à Época Moderna em meios urbanos em Portugal

Ana Lema Seabra

1659 O Caminho Português Interior de Santiago como eixo viário na Idade Média Pedro Azevedo

1665 Morfologia Urbana: Um exercício em torno do Castelo de Ourém André Donas-Botto / Jaqueline Pereira

1677 Intervenção arqueológica na Rua Marquês de Pombal/Largo do Espírito Santo (Bucelas, Loures)

Florbela Estêvão / Nathalie Antunes-Ferreira / Dário Ramos Neves / Inês Lisboa

1691 O Cemitério Medieval do Poço do Borratém e a espacialidade funerária na cidade de Lisboa Inês Belém / Vanessa Filipe / Vasco Noronha Vieira / Sónia Ferro / Rodrigo Banha da Silva

1705 Um Espaço Funerário Conventual do séc. XV em Lisboa: o caso do Convento de São Domingos da Cidade Sérgio Pedroso / Sílvia Casimiro / Rodrigo Banha da Silva / Francisca Alves Cardoso

\section{9. Época Moderna e Contemporânea}

1721 Arqueologia Moderna em Portugal: algumas reflexões críticas em torno da quantificação de conjuntos cerâmicos e suas inferências históricas e antropológicas Rodrigo Banha da Silva / André Bargão / Sara da Cruz Ferreira

1733 Faianças de dois contextos entre os finais do século XVI e XVIII do Palácio dos Condes de Penafiel, Lisboa

Martim Lopes / Tomás Mesquita 
1747 Um perfil de consumo do século XVIII na foz do Tejo: O caso do Mercado da Ribeira, Lisboa Sara da Cruz Ferreira / Rodrigo Banha da Silva / André Bargão

1761 Os Cachimbos dos Séculos XVII e XVIII do Palácio Mesquitela e Convento dos Inglesinhos (Lisboa)

Inês Simão / Marina Pinto / João Pimenta / Sara da Cruz Ferreira / André Bargão / Rodrigo Banha da Silva

1775 "Tomar os fumos da erua que chamão em Portugal erua sancta». Estudo de Cachimbos provenientes da Rua do Terreiro do Trigo, Lisboa

Miguel Martins de Sousa / José Pedro Henriques / Vanessa Galiza Filipe

1787 Cachimbos de Barro Caulínitico da Sé da Cidade Velha (República de Cabo Verde)

Rodrigo Banha da Silva / João Pimenta / Clementino Amaro

1801 Algumas considerações sobre espólio não cerâmico recuperado no Largo de Jesus (Lisboa) Carlos Boavida

1815 Adereços de vidro, dos séculos XVI-XVIII, procedentes do antigo Convento de Santana de Lisboa (anéis, braceletes e contas)

Joana Gonçalves / Rosa Varela Gomes / Mário Varela Gomes

1837 Da ostentação, luxo e poder à simplicidade do uso quotidiano: arqueologia e simbologia de joias e adornos da Idade Moderna Portuguesa Jéssica Iglésias

1849 Os amuletos em Portugal - dos objetos às superstições: o coral vermelho Alexandra Vieira

1865 Cerâmicas de Vila Franca de Xira nos séculos XV e XVI Eva Pires

1879 «Não passa por teu o que me pertence». Marcas de individualização associadas a faianças do Convento de Nossa Senhora de Aracoeli, Alcácer do Sal Catarina Parreira / Íris Fragoso / Miguel Martins de Sousa

1891 Cerâmica de Leiria: alguns focos de produção

Jaqueline Pereira / André Donas-Botto

1901 Os Fornos na Rua da Biquinha, em Óbidos Hugo Silva / Filipe Oliveira

1909 A casa de Pêro Fernandes, contador dos contos de D. Manuel I: o sítio arqueológico da Silha do Alferes, Seixal (século XVI) Mariana Nunes Ferreira

1921 O Alto da Vigia (Sintra) e a vigilância e defesa da costa Alexandre Gonçalves / Sandra Santos

1937 O contexto da torre sineira da Igreja de Santa Maria de Loures Paulo Calaveira / Martim Lopes

1949 A Necrópole do Hospital Militar do Castelo de São Jorge e as práticas funerárias na Lisboa de Época Moderna Susana Henriques / Liliana Matias de Carvalho / Ana Amarante / Sofia N. Wasterlain

1963 SAND - Sarilhos Grandes Entre dois Mundos: o adro da Igreja e a Paleobiologia dos ossos humanos recuperados

Paula Alves Pereira / Roger Lee Jesus / Bruno M. Magalhães

1975 Expansão urbana da vila de Cascais no século XVII e XVIII: a intervenção arqueológica na Rua da Vitória no 15 a 17

Tiago Pereira / Vanessa Filipe

1987 Novos dados para o conhecimento do Urbanismo de Faro em época Moderna Ana Rosa 
1995 Um exemplo de Arqueologia Urbana em Alcoutim: o Antigo Edifício dos CTT Marco Fernandes / Marta Dias / Alexandra Gradim / Virgílio Lopes / Susana Gómez Martínez

2007 Palácio dos Ferrazes (Rua das Flores/Rua da Vitória, Porto): a cocheira de Domingos Oliveira Maia

Francisco Raimundo

2021 As muitas vidas de um edifício urbano: História, Arqueologia e Antropologia no antigo Recreatório Paroquial de Penafiel Helena Bernardo / Jorge Sampaio / Marta Borges

2035 O convento de Nossa Senhora da Esperança de Ponta Delgada: o contributo da arqueologia para o conhecimento de um monumento identitário João Gonçalves Araújo / N’Zinga Oliveira

2047 Arqueologia na ilha do Corvo... em busca da capela de Nossa Senhora do Rosário Tânia Manuel Casimiro / José Luís Neto / Luís Borges / Pedro Parreira

2059 Perdidos à vista da Costa. Trabalhos arqueológicos subaquáticos na Barra do Tejo Jorge Freire / José Bettencourt / Augusto Salgado

2071 Arqueologia marítima em Cabo Verde: enquadramento e primeiros resultados do projecto CONCHA

José Bettencourt / Adilson Dias / Carlos Lima / Christelle Chouzenoux / Cristóvão Fonseca / Dúnia Pereira / Gonçalo Lopes / Inês Coelho / Jaylson Monteiro / José Lima / Maria Eugénia Alves / Patrícia Carvalho / Tiago Silva

2085 Trabalhos arqueológicos na Cidade Velha (Ribeira Grande de Santiago, Cabo Verde): reflexões sobre um projecto de investigação e divulgação patrimonial André Teixeira / Jaylson Monteiro / Mariana Mateus / Nireide Tavares / Cristovão Fonseca / Gonçalo C. Lopes / Joana Bento Torres / Dúnia Pereira / André Bargão / Aurélie Mayer / Bruno Zélie / Carlos Lima / Christelle Chouzenoux / Inês Henriques / Inês Pinto Coelho / José Lima / Patrícia Carvalho / Tiago Silva

2103 A antiga fortificação de Quelba / Khor Kalba (E.A.U.). Resultados de quatro campanhas de escavações, problemáticas e perspectivas futuras Rui Carita / Rosa Varela Gomes / Mário Varela Gomes / Kamyar Kamyad

2123 Colónias para homens novos: arqueologia da colonização agrária fascista no noroeste ibérico Xurxo Ayán Vila / José Mạ . Señorán Martín 


\title{
O SÍTIO ACHEULENSE DO PLISTOCÉNICO MÉDIO DA GRUTA DA AROEIRA
}

\author{
Joan Daura ${ }^{1,2}$, Montserrat Sanz ${ }^{1,2}$, Filipa Rodrigues ${ }^{2}$, Pedro Souto $^{3}$, João Zilhão ${ }^{2,4,5}$
}

\begin{abstract}
RESUMO
Datado de cerca de 400 ka (estádio isotópico marinho 11), o sítio da Gruta da Aroeira (Torres Novas, Portugal)é uma das poucas jazidas do Plistocénico Médio que entregou um crânio fóssil de hominídeo associado a bifaces acheulenses em contexto de gruta. A nossa abordagem multi-analítica do registo arqueológico incidiu sobre diferentes categorias de vestígios: o crânio humano (Aroeira 3), os restos faunísticos, os restos de combustão e a indústria lítica. O crânio fóssil Aroeira 3 possui um labirinto ósseo primitivo e apresenta uma fractura óssea perimortem. A indústria lítica sugere uma mobilidade limitada; as actividades de talhe realizadas no sítio incluem a exploração de núcleos, mas os bifaces foram introduzidos já como utensílios acabados. A análise dos restos faunísticos confirma a presença do primata Macaca sylvanus e documenta uma grande diversidade de cervídeos, incluindo o veado mediterrânico Haploidocerus mediterraneus, nunca antes documentado no Plistocénico Médio da Península Ibérica. A reconstrução paleo-ambiental baseada nos pequenos vertebrados indica uma paisagem florestal aberta com condições semi-húmidas. Por outro lado, a presença de subprodutos de combustão prova utilização controlada do fogo entre as populações do Acheulense.
\end{abstract}

Palavras-chave: Restos humanos, Bifaces, Fogo.

\begin{abstract}
Dated to ca. 400 ka (Marine Isotope Stage 11), the site of Gruta da Aroeira (Torres Novas, Portugal) is one of the very few Middle Pleistocene localities that have yielded a fossil hominin cranium associated with Acheulean bifaces, in a cave context. Our multi-analy tical approach to the site's archaeological record focused on different aspects: the human cranium (Aroeira 3), the faunal remains, the use of fire, and the lithic industry. The Aroeira 3 fossil cranium displays a primitive bony labyrinth and a perimortem bone fracture. The lithic assemblage suggests limited mobility, with on-site knapping; the bifaces, however, were brought to the site as finished tools. Among the faunal remains, the primate Macaca sylvanus is present and cervids, including the Mediterranean deer Haploidocerus mediterraneus, previously undocumented in the Middle Pleistocene of the Iberian Peninsula, predominate. Paleoenvironmental reconstruction using the small vertebrate assemblage suggests an open woodland landscape with semi-humid conditions. The presence of combustion by-products supports the controlled use of fire by the peoples of the Acheulean.
\end{abstract}

Keywords: Human remains, Bifaces, Fire.

1. Grup de Recerca del Quaternari (GRQ) del Seminari Estudis i Recerques Prehistòriques (SERP), Dept. d'Història i Arqueologia. Universitat de Barcelona; J. Daura: jdaura_lujan@ub.edu; M. Sanz: montsesanzborras@ub.edu

2. UNIARQ-Centro de Arqueologia da Universidade de Lisboa. Faculdade de Letras. Universidade de Lisboa, 16oo-214 Lisbon, Portugal; F. Rodrigues; a.filipa.castro.rodrigues@gmail.com

3. STEA - Sociedade Torrejana de Espeleologia e Arqueologia, Quinta da Lezíria, 2350-510 Torres Novas, Portugal; P. Souto: pedrojsouto@gmail.com

4. Institució Catalana de Recerca i Estudis Avançats (ICREA), Passeig Lluís Companys 23, o8010 Barcelona, Spain; J. Zilhão: joao.zilhao@ub.edu

5. Departament d'Història i Arqueologia. Universitat de Barcelona, Carrer Montalegre, 6, o8oor Barcelona, Spain. 


\section{INTRODUÇÃO}

O Plistocénico Médio ( 700-125 ka) é um período durante o qual se observam duas importantes novidades: a expansão do Acheulense (Santonja e Villa 2006) e as primeiras provas da utilização generalizada, sistemática e controlada do fogo (Roebroeks e Villa 2011). Tanto na Península Ibérica como no resto da Europa, porém, o conhecimento do Acheulense em geral, e do Estádio Isotópico Marinho (MIS) 11 em particular, está fortemente determinado por sítios de ar livre em contexto de terraço fluvial (Santonja et al. 2014, Méndez-Quintas et al. 2018, 2019) ou de margem de lago (Santonja et al. 2016). Apesar de serem os mais numerosos, os sítios de ar livre apresentam uma série de condicionantes, nomeadamente a nível sedimentológico e dos processos pós-deposicionais, que limitam o seu potencial para a reconstrução do passado.

Menos numerosos, os sítios de gruta representam no entanto contextos mais "fechados" onde as acumulações de materiais arqueológicos resultam, normalmente, de actividades humanas realizadas in loco. Ainda assim, existem outros factores que podem intervir na génese dessas acumulações, tais como processos geológicos ou agentes biológicos (por exemplo, os carnívoros). Este tipo de sítios oferece um leque mais amplo de possibilidades de estudo e permite a aplicação de múltiplas técnicas de análise. Além disso, os sítios de gruta e os abrigos constituem, pela sua própria natureza, bons exemplos de residential camp site com potencial para a reconstrução das actividades dos grupos de caçadores-recolectores.

$\mathrm{Na}$ Península Ibérica, os sítios de gruta do Paleolítico Inferior são em número limitado: Cueva del Ángel (Barroso Ruíz et al. 2011), Galería (García-Medrano et al. 2014) ou La Garma (Arias e Ontañón 2012).

A descoberta da Gruta da Aroeira veio acrescentar a este pequeno grupo uma das poucas jazidas do Plistocénico Médio que possui um registo arqueológico claramente acheulense, com presença de bifaces, restos humanos e provas claras de uso e controlo do fogo. Apresentam-se neste artigo os últimos desenvolvimentos no conhecimento deste sítio arqueológico desde a descoberta em 2014, e publicação em 2017, do crânio Aroeira 3 (Daura et al. 2017b, 2017a, 2017c). Os estudos mais recentes centraram-se no crânio, nomeadamente a nível do ouvido interno e da tafonomia, na indústria lítica, nos restos faunísticos e, finalmente, no estudo das provas de fogo.

\section{O SÍTIO}

A Gruta da Aroeira ( $39^{\circ} 30^{\prime} 20^{\prime \prime} \mathrm{N}$; $08^{\circ} 36^{\prime} 57^{\prime \prime} \mathrm{W}$ ) (Figura 1) localiza-se no complexo cársico do Almonda (Torres Novas, Portugal), concretamente no alto da escarpa sobre a nascente que também alberga outras cavidades com um registo arqueológico já explorado (como a Gruta da Oliveira e a Lapa dos Coelhos). O sítio foi descoberto em 1991, a partir de vestígios arqueológicos identificados no interior do sistema cársico, nomeadamente nas chamadas Galerias Pesadas (Zilhão et al. 1993). Posteriormente, localizou-se a entrada colmatada - Gruta da Aroeira - e realizaram-se as primeiras escavações arqueológicas (1997-2002), as quais incidiram também sobre a zona externa da jazida, a chamada Brecha das Lascas, ou seja, a zona da cavidade que a erosão e o recuo da escarpa deixaram ao ar livre (Marks et al. 2002a, 2002b, Trinkaus et al. 2003). Em 2013 teve início uma nova fase do projecto, focada na escavação dos níveis inferiores da sequência.

Do ponto de vista crono-estratigráfico, a sequência apresenta cinco fases. A Fase 5 corresponde ao momento anterior à abertura da gruta ao exterior e inclui a camada XII (unidade 3) e a formação da grande coluna estalagmítica que divide a sala principal; a camada mais exterior desta coluna foi datada de $406 \pm 30 \mathrm{ka}$, o que dá uma idade máxima para os eventos posteriores. A Fase 4 está representada pelas camadas X e XI, por sua vez seladas por uma espessa crosta estalagmítica cuja base está datada de 418/+37/-27 ka. A conjugação destas duas datações restringe a acumulação do preenchimento acheulense ao intervalo compreendido entre 390 e $436 \mathrm{ka}$. A Fase 3 corresponde a um hiato de sedimentação, durante o qual se formaram tanto essa crosta estalagmítica (cuja parte superior tem uma idade de $326.4 \pm 13.4 \mathrm{ka}$ ) como uma outra que sela a Brecha das Lascas (para essa outra crosta temos uma idade mínima dada pela datação de $278.5 \pm 12.7$ ka obtida para uma estalagmite que sobre ela cresceu). A Fase 2 relaciona-se com o abatimento de parte do tecto, nas fiadas 10-14 da quadrícula de escavação, e subsequente acumulação de um depósito sedimentar. A Fase 1 corresponde à formação da crosta estalagmítica "AROr", que cobre a totalidade do preenchimento na zona interior da jazida e cuja base foi datada de $44.8 \pm 2.0 \mathrm{ka}$. Estes resultados permitem propor a seguinte correlação com o registo global: Fase 5, MIS 11c ou anterior; Fase 4, MIS 11c, 390- 
420 ka; Fase 3, MIS 7a-11b, 190-39o ka; Fase 2, MIS 4-7a, 6o-19o ka; e Fase 1, MIS 3c 40-6o ka (Daura et al. 2017c).

\section{RESTOS HUMANOS}

O sítio da Aroeira ofereceu três restos humanos. Dois são dentes isolados (Aroeira 1 e 2) recuperados durante as campanhas de 1997-2002 (Trinkaus et al., 2003); o terceiro é o crânio fragmentado (Aroeira 3) de um indivíduo adulto (Daura et al. 2017c). Este último corresponde a uma porção considerável do lado direito da caixa craniana a que falta o occipital mas que conserva parte do lado esquerdo da escama frontal e do toro supraorbital, bem como a região interorbital (incluindo a parte vertical dos ossos nasais). O fóssil Aroeira 3 apresenta alguns traços primitivos presentes em certos fósseis do Plistocénico Médio mas ausentes nos Neandertais (Daura et al. 2017a).

A aplicação da microtomografia computorizada (mCT) ao crânio Aroeira 3 permitiu a reconstrução virtual da estrutura do ouvido interno, disponibilizando assim informação sobre a respectiva morfologia (Conde-Valverde et al., 2018) e possibilitando a sua comparação com outros restos humanos actuais e fósseis. A análise revelou a ausência de características derivadas, próprias dos Neandertais: não se observam nem as proporções típicas destes últimos nem a posição inferior da parte posterior do canal, outra das características mais diagnosticantes do respectivo labirinto ósseo. Com base nestas características, Aroeira 3 é um fóssil mais primitivo que os da Sima de los Huesos de Atapuerca (SH). Comum a Aroeira 3 e aos fósseis de Atapuerca (SH) é porém a forma da volta basal da cóclea, diferente da que se encontra entre os Neandertais.

Estes resultados proporcionam novos contributos para o conhecimento das dinâmicas populacionais do Plistocénico Médio, na origem do clado neandertal. Por exemplo, apesar da cercania geográfica e cronologia idêntica, a existência de diferenças significativas entre o ouvido interno de Aroeira 3 e o dos fósseis de Atapuerca (SH) sugere um certo grau de isolamento demográfico.

O estudo tafonómico do crânio Aroeira 3 proporciona informação sobre a possível causa de morte do indivíduo e o papel dos agentes biológicos e geológicos na formação do depósito. O crânio está partido obliquamente em relação ao plano sagital, com a porção preservada orientada diagonalmente, desde a parte anterior do arco supraorbital esquerdo, atravessando a linha média imediatamente antes do bregma, e continuando no sentido posterior em direcção ao astério direito. Observa-se perda substancial da superfície externa dos arcos supraorbitais direito e esquerdo e da escama frontal.

A maioria das fracturas apresenta características próprias das lesões post-mortem. A fractura da região posterior do osso parietal, contudo, apresenta características mais habitualmente presentes nas fracturas ósseas perimortem (Figura 2). A perda de matéria óssea na escama frontal e no arco supraorbital pode ser atribuída a diferentes causas, não sendo possível descartar totalmente um evento traumático como origem dessas alterações, mas não foram observadas lesões que pudessem ter resultado de violência interpessoal. Tão-pouco foi identificada qualquer prova de modificação antropogénica ou por carnívoros. Como o canibalismo e o tratamento secundário do cadáver podem ser postos de parte, acidente é a explicação mais plausível para a fractura craniana (Sanz et al. 2018).

\section{INDÚSTRIA LÍTICA}

A indústria lítica procedente da zona escavada em 2013-2017 corresponde a um conjunto de 393 artefactos, incluindo bifaces acheulenses $(\mathrm{n}=17)$ (Figura 3 ) e outras peças bifaciais $(n=2)$, outras peças retocadas $(n=45)$, núcleos $(n=47)$, lascas e fragmentos de lascas ( $n=207$ ), e seixos (testados ou não, e talvez manuportes) ( $\mathrm{n}=99)$. A amostra inclui sete tipos diferentes de rochas e minerais ígneos, sedimentares e metamórficos, mas a matéria-prima de eleição é o quartzito, sendo o sílex escasso (mas existem bifaces talhados sobre ambos). O método Levallois não está representado.

A análise de núcleos e lascas mostra que o talhe seguiu principalmente um esquema centrípeto (Daura et al., 2018). Os núcleos esgotados, tanto de quartzo como de quartzito, apresentam mais frequentemente uma organização bipiramidal, embora uma pequena percentagem seja unipolar ou bipolar; a debitagem bipolar sobre bigorna está representada por alguns exemplares de quartzo. Um número significativo de núcleos foram pouco trabalhados, o que parece reflectir uma exploração oportunista. Embora haja também alguns núcleos unifaciais centrípetos, a maioria dos núcleos são discóides e foram talhados bifacialmente mediante levantamentos 
centrípetos ou cordais utilizando superfícies alternadas. A elevada percentagem de lascas corticais (inteiramente ou em mais de 50\% do anverso) indica a realização de sequências de talhe completas.

Morfologicamente, os 17 bifaces identificados neste conjunto são cordiformes, lanceolados e amigdalóides. Na maioria das peças não foi possível determinar o suporte original, mas em alguns casos tratava-se de lascas. A maioria destes bifaces são de pequena dimensão: ou porque foram feitos pequenos de raiz, ou por corresponderem à fase final da vida útil destes artefactos, antes do respectivo abandono.

A colecção inclui também utensílios sobre lasca. $\mathrm{Na}$ maior parte dos casos trata-se de raspadores simples cujos bordos laterais foram modificados por retoque directo, mas alguns dos raspadores apresentam retoque bifacial. Os denticulados são a segunda categoria mais numerosa.

Os bordos e superfícies estão bem conservados. Vários bifaces e lascas ostentam marcas que proporcionam informação sobre as matérias-primas trabalhadas, que em geral são materiais duros como a madeira, a haste ou o osso. Onde foi possível identificar tanto a dureza do material como a direcção do movimento, os vestígios apontam, na maioria dos casos, para actividades de transformação de madeira por percussão, tanto longitudinal como transversal. Em dois bifaces, o polimento que denota percussão sobre madeira está associado ao esmagamento e abrasão do gume utilizado, e em três outros está associado a trabalho de corte (indicado pelo tipo de desgaste dos bordos laterais).

\section{RESTOS FAUNÍSTICOS}

Os restos de fauna com marcas de modificação antropogénica provêm da camada X e estão muito fragmentados, pelo que os elementos anatómicos identificáveis se limitam a peças dentárias isoladas, ossos dos membros, e epífises maciças. A camada XI contém restos acumulados por outros agentes biológicos. No total, foram coordenados na camada Xb 209 restos, na maioria cervídeos (NISP=58) e equídeos $(\mathrm{NISP}=46)$. Entre as espécies mais raras contam-se o castor (Castor fiber NISP=3), um rinoceronte $(\mathrm{NISP}=2)$ (provavelmente Stephanorhinus cf. hundsheimensis), o urso ( $\mathrm{NISP}=4$ ) (Ursus sp.), e ainda um grande bovídeo (Bos/Bison), um caprídeo (Caprinae) e uma tartaruga terrestre (Testudo sp.) (NISP = I de cada). Os desenvolvimentos mais significativos ao nível do estudo da fauna correspondem ao estudo i) dos cervídeos, ii) dos restos de cercopitecídeos e iii) da microfauna.

Em relação aos cervídeos, durante os trabalhos de campo previamente desenvolvidos no sítio (1997-2002) foram identificadas duas espécies de veado, Cervus elaphus e Dama vallonnetensis (Marks et al. 2002b). Já os restos de cervídeos recuperados durante os trabalhos mais recentes incluem quatro espécies de veado: Cervus elaphus, Praedama cf. savini, Haploidoceros mediterraneus, e Dama cf. vallonnetensis, tornando a Gruta da Aroeira no primeiro sítio da Península Ibérica em que o género Haploidoceros é documentado no Plistocénico Médio. Praticamente todos os cervídeos documentados no sítio revelam um certo grau de endemismo, incluindo modificações evolutivas do crânio, das hastes e da dentição ou uma redução do tamanho do corpo. A invulgar riqueza dos cervídeos da Gruta da Aroeira pode estar relacionada com as condições biogeográficas específicas do Plistocénico Médio da Península Ibérica. Assim, se a ligação geográfica da Península Ibérica com a zona temperada da Eurásia ocidental facilitou a chegada de cervídeos de origem paleárctica, impediu por outro lado a entrada de ruminantes de zonas mais quentes e áridas. O carácter endémico destes cervídeos e a biodiversidade da Península Ibérica devem ser tidos em conta na avaliação da paleobiogeografia dos hominídeos ibéricos, das suas estratégias de caça, e da sua economia (Croitor et al. 2019).

Brugal (2004), Marks et al. (2002a, 2002b) e Trinkaus et al. (2003) mencionam a recuperação de restos de macaco durante a primeira fase das escavações. Atribuídos a Macaca sylvanus ? florentina, esses restos ainda não foram descritos. As escavações de 20132017 deram uma mandíbula de macaco juvenil no topo da camada X: o exemplar ARO \#934. O fóssil preserva a sínfise e a maioria dos dois corpos mandibulares, bem como a maioria do ramo esquerdo, excepto o processo coronóide e o côndilo mandibular. $\mathrm{O} \mathrm{dP}_{3}$ e $\mathrm{M} 1$ direitos e a série $\mathrm{dP}_{4}-\mathrm{M}_{1}$ esquerda estão presentes e apresentam erupção completa, mas o $\mathrm{dP}_{3}$ esquerdo não se conservou. A reconstrução virtual a partir de imagens $C T$ revela, dentro dos respectivos alvéolos, os germes de incisivos, caninos, pré-molares e segundos molares permanentes. A morfologia, tamanho e proporções dos dentes, tanto decíduos como permanentes, indicam que o fóssil da Aroeira corresponde provavelmente a um indivíduo feminino de M. sylvanus subsp. - menor 
do que Paradolichopithecus spp. mas maior do que Macaca majori (Alba et al. 2019)

E. Peman realizou um estudo preliminar dos mamíferos pequenos (insectívoros, morcegos e roedores) recuperados durante as campanhas de 1997-1999, infelizmente com um contexto estratigráfico pouco preciso (Marks et al. 2002b). Os pequenos vertebrados das actuais escavações (camada Xc) incluem pelo menos 17 taxa. Os répteis estão representados por restos indeterminados de Salamandridae (NISP=1), Pelodytes sp. (NISP=2), Bufo spinosus $(\mathrm{NISP}=2)$, Anura indet $(\mathrm{NISP}=1)$, Lacertidae indet $(\mathrm{NISP}=2)$, cf. Coronella girondica (NISP=1), Natrix cf. maura (NISP=3) e Ophidia indet (NISP=5). Os pequenos mamíferos estão representados por Sorex sp. (12), Crocidura sp., Rhinolophus ferrumequinum, (2), Rhinolophus sp. (tamanho pequeno) (3), Myotis myotis (12), Myotis sp. (tamanho médio) (3), cf. Miniopterus schreibersii (2), Iberomys brecciensis (61), Pliomys episcopalis (4), Apodemus cf. A. flavicollis (134), Allocricetus bursae (47) e Eliomys quercinus (17). A reconstrução paleo-ambiental, utilizando os pequenos vertebrados como indicador climático, aponta para uma paisagem de floresta aberta e para condições relativamente suaves e húmidas, provavelmente relacionadas com o final do MIS i1c.

\section{FOGO}

Foram recuperados restos de ossos queimados, carvões e vários seixos provavelmente queimados (Figura 4). Estes elementos foram encontrados em dois horizontes arqueológicos distintos e separados, numa área reduzida da caverna, sugerindo utilização controlada do fogo. A concentração situada na parte basal da camada X (nível Xc) parece ser a mais importante.

Os ossos termo-alterados são 43. A intensidade da alteração é variável, estando representados todos os termos da escala de cores proposta por Stiner et al. (1995) para o estudo de restos arqueológicos, incluindo alguns calcinados (Figura 4). A análise por espectroscopia de raios $\mathrm{X}$ confirma que a coloração negra não é manganês. Trata-se, em todos os casos, de fragmentos pequenos e a termo-alteração dos ossos foi confirmada por análise FTIR. Oito objectos líticos apresentam alterações cromáticas (Figura 4) mas, como as propriedades magnéticas não são concludentes, não é possível assegurar que as alterações em causa tenham sido causadas por exposição ao fogo.

\section{CONCLUSÕES}

Da escavação arqueológica da camada X da Gruta da Aroeira, datada de há cerca de 400 ooo anos, podemos extrair as seguintes conclusões:

- Crânio Aroeira 3: O labirinto ósseo revelou uma ausência de características derivadas neandertais; trata-se de um labirinto ósseo bastante primitivo, mais semelhante ao que se encontra entre formas mais antigas do género Homo. Uma morte natural, acidental ou por doença, é a explicação mais plausível, neste caso como no da maioria dos casos de restos humanos isolados.

- Indústria lítica: O território percorrido pelos ocupantes da gruta parece ter estado limitado às terras baixas da planície do Tejo. O sítio regista talhe a partir de fontes de matéria-prima local e descarte de artefactos trazidos de outros locais. Os utensílios foram utilizados para trabalhar madeira e provavelmente também no processamento de carcaças. A associação deste conjunto lítico com um crânio humano reforça a noção de que a emergência e difusão do Acheulense na Europa não podem ser relacionadas com uma entidade específica da taxonomia corrente em Paleontologia Humana e têm de ser entendidas nos seus próprios termos, como processos culturais.

- Restos faunísticos: Estão representados quatro tipos de cervídeos: Praedama cf. savini, Cervus elaphus, Haploidoceros mediterraneus e Dama cf. vallonnetensis. O tamanho relativamente pequeno do corpo significa que teriam constituído presas ideais, permitindo que as carcaças fossem transportadas para o acampamento-base; trata-se de adultos jovens e de adultos, ou seja, os alvos típicos dos caçadores paleolíticos. Os pequenos vertebrados indicam uma paisagem dominada por floresta aberta e condições relativamente suaves e semi-húmidas.

- Fogo: Foram identificados subprodutos de combustão, nomeadamente ossos queimados (alguns dos quais expostos a temperaturas elevadas), carvão e seixos possivelmente alterados pelo calor, confirmando o uso controlado do fogo entre as populações do Plistocénico Médio do sudoeste da Europa. 


\section{AGRADECIMENTOS}

Esta investigação foi apoiada pela FCT (Fundação para a Ciência e a Tecnologia, Portugal) através dos projetos PTDC/HIS-ARQ/o98164/2008 e PTDC/ HAR-ARQ/30413/2017). O trabalho de campo foi financiado pela Câmara Municipal de Torres Novas e pela FCT, com apoio logístico da Fábrica de Papel A Renova e da STEA (Sociedade Torrejana de Espelologia e Arqueologia). A investigação foi ainda apoiada pelos projectos HAR2017-86509 e 2017SGR-ooo11. J.D. foi financiado através de um contrato Ramon y Cajal (RYC-2015-17667) e M.S. através de um contrato Juan de la Cierva (IJCI-2017-33908).

\section{BIBLIOGRAFIA}

ALBA, David M.; DAURA, Joan; SANZ, Montserrat; SANTOS, Elena; YAGÜE, Almudena S.; DELSON, Eric; ZILHÃO, João (2019) - New macaque remains from the Middle Pleistocene of Gruta da Aroeira (Almonda karst system, Portugal). Journal of Human Evolution. 131, pp. 40-47.

ARIAS, Pablo; ONTAÑ́́N, Roberto (2012) - Chapter 8: La Garma (Spain): long-term human activity in a karst system. Em BERGSVIK, Knut Andreas; SKEATES, Robin, eds. - Caves in Context: The Cultural Significance of Caves and Rockshelters in Europe pp. 101-1017.

BARROSO RUÍZ, Cecilio; BOTELLA ORTEGA, Daniel; CAPARRÓS, Miguel; MOIGNE, Anne Marie; CELIBERTI, Vincenzo; TESTU, Agnès; BARSKY, Deborah; NOTTER, Olivier; RIQUELME CANTAL, José Antonio; RODRÍGUEZ, Manuel Pozo; CARRETERO LEÓN, María Isabel; MONGE GÓMEZ, Guadalupe; KHATIB, Samir; SAOS, Thibaud; GREGOIRE, Sophie; BAILÓN, Salvador; GARCÍA SOLANO, José Antonio; CABRAL MESA, Antonio Luis; DJERRAB, Abderrezak; GEORGE HEDLEY, Ian; ABDESSADOK, Salah; BATALLA LLASAT, Gerard; ASTIER, Nicolas; BERTIN, Læticia; BOULBES, Nicolas; CAUCHE, Dominique; FILOUX, Arnaud; HANQUET, Constance; MILIZIA, Christelle; MOUTOUSSAMY, José; ROSSONI, Elena; VERDÚ BERMEJO, Luis; DE LUMLEY, Henry (2011) - The Cueva del Angel (Lucena, Spain): An Acheulean hunters habitat in the South of the Iberian Peninsula. Quaternary International. 243:1, pp. 105-126.

BRUGAL, Jean-Philip (2004) - First Middle Pleistocene faunas with primates ( Homo, Macaca) from Estremadura (Portugal). - $18^{\text {th }}$ International Senckenberg Conference,VI International Paleontological Colloquium in Weimar, $25^{\text {th }}-$ $30^{\text {th }}$ April 2004 Weimar: Terra Nostra, pp. 82-83.

CROITOR, Roman; SANZ, Montserrat; DAURA, Joan (2019) - Deer remains from the Middle Pleistocene site of Gruta da Aroeira (Portugal): Iberian faunal endemism and implications for hominin paleobiogeography. Quaternary Science Reviews. 225, p. 106022.
DAURA, Joan; SANZ, Montserrat; ARSUAGA, Juan-Luis; QUAM, Rolf; HOFFMANN, Dirk L.; ORTEGA, María Cruz; SANTOS, Elena; GÓMEZ, Sandra; RUBIO, Angel; VILLAESCUSA, Lucía; SOUTO, Pedro; MAURICIO, João; RODRIGUES, Filipa; FERREIRA, Artur; GODINHO, Pa; TRINKAUS, Erik; ZILHÃO, João (2017a) - The Middle Pleistocene Human Cranium from Gruta da Aroeira Acheulian site (Almonda Karst System, Torres Novas, Portugal). American Journal of Physical Anthropology.162:S64, pp. 157-158.

DAURA, Joan; SANZ, Montserrat; ARSUAGA, Juan-Luis; QUAM, Rolf; HOFFMANN, Dirk L.; ORTEGA, María Cruz; SANTOS, Elena; GÓMEZ, Sandra; RUBIO, Angel; VILLAESCUSA, Lucía; SOUTO, Pedro; RODRIGUES, Filipa; MAURICIO, João; FERREIRA, Artur; GODINHO, Paulo; TRINKAUS, Erik; ZILHÃO, João (2017b) - O crânio humano acheulense do plistocénico médio da Gruta da Aroeira. - Arqueologia em Portugal / 2017 - Estado da Questão Lisboa, Portugal, Associação dos Arqueólogos Portugueses, pp. 295-302.

DAURA, Joan; SANZ, Montserrat; ARSUAGA, Juan Luis J.L.; HOFFMANN, Dirk L. D.L.; QUAM, R.M. Rolf M.; ORTEGA, M.C. María Cruz; SANTOS, Elena; GÓMEZ, Sandra; RUBIO, Angel; VILLAESCUSA, Lucía; SOUTO, Pedro; MAURICIO, João; RODRIGUES, Filipa; FERREIRA, Artur; GODINHO, Paulo; TRINKAUS, Erik; ZILHÃO, João (2017c) - New Middle Pleistocene hominin cranium from Gruta da Aroeira (Portugal). Proceedings of the National Academy of Sciences. 114:13, pp. 3397-3402.

GARCÍA-MEDRANO, Paula; OLLÉ, Andreu; MOSQUERA, Marina; CÁCERES, Isabel; DÍEZ, Carlos; CARBONELL, Eudald (2014) - The earliest Acheulean technology at Atapuerca (Burgos, Spain): Oldest levels of the Galería site (GII Unit). Quaternary International. 353, pp. 170-194.

MARKS, An E; MONIGAL, Katherine; CHABAI, Victor P; BRUGAL, Jean-Philip; GOLDBERG, Paul; HOCKETT, Bryan; PEMÁN, Eduardo; ELORZA, Mikelo; MALLOLL, Carolina (2002a) - Excavations at the late Middle Pleistocene cave of Galeria Pesada: 1997/1999. O Arqueólogo Português. 20, pp. 7-38.

MARKS, Anthony E; BRUGAL, Jean-Philip; CHABAI, Victor P; MONIGAL, Katherine; GOLDBERG, Paul; HOCKETT, Bryan; PEMAN, Eduardo; ELORZA, Mikelo; MALLOLL, Carolina (2002b) - Le gisement Pléistocène moyen de Galeria Pesada, (Estrémadure, Portugal): premiers résultats. Paléo. 14, pp. 77-100.

MÉNDEZ-QUINTAS, Eduardo; DEMURO, Martina; ARNOLD, Lee J; DUVAL, Mathieu; PÉREZ-GONZÁLEZ, Alfredo; SANTONJA, Manuel (2019) - Insights into the late stages of the Acheulean technocomplex of Western Iberia from the Arbo site (Galicia, Spain). Journal of Archaeological Science: Reports. 27, p. 101934. 
MÉNDEZ-QUINTAS, Eduardo; SANTONJA, Manuel; PÉREZ-GONZÁLEZ, Alfredo; DUVAL, Mathieu; DEMURO, Martina; ARNOLD, Lee J (2018) - First evidence of an extensive Acheulean large cutting tool accumulation in Europe from Porto Maior (Galicia, Spain). Scientific Reports. 8:1, p. 3082.

ROEBROEKS, Wil; VILLA, Paola (2011) - On the earliest evidence for habitual use of fire in Europe. Proceedings of the National Academy of Sciences. 108:13, pp. 5209-5214.

SANTONJA, Manuel; PÉREZ-GONZÁLEZ, Alfredo; DOMÍNGUEZ-RODRIGO, Manuel; PANERA, Joaquín; RUBIO-JARA, Susana; SESÉ, Carmen; SOTO, Enrique; ARNOLD, Lee James; DUVAL, Mathieu; DEMURO, Martina; ORTIZ, José E.; DE TORRES, Trinidad; MERCIER, Norbert; BARBA, Rebeca; YRAVEDRA, José (2014) - The Middle Paleolithic site of Cuesta de la Bajada (Teruel, Spain): a perspective on the Acheulean and Middle Paleolithic technocomplexes in Europe. Journal of Archaeological Science. 49, pp. 556-571.

SANTONJA, Manuel; PÉREZ-GONZÁlEZ, Alfredo; PANERA, Joaquín; RUBIO-JARA, Susana; MÉNDEZ-QUINTAS, Eduardo (2016) - The coexistence of Acheulean and Ancient Middle Palaeolithic techno-complexes in the Middle Pleistocene of the Iberian Peninsula. Quaternary International. 411, pp. 367-377.

SANTONJA, Manuel; VILLA, Paola (2006) - The Acheulianof Western Europe. Em GOREN-INBAR, Naama; SHARON, Gonen, eds. - Axe Age-Acheulian Tool-making from Quarry to Discard London: Equinox, pp. 429-478.

SANZ, Montserrat; SALA, Nohemi; DAURA, Joan; PANTOJA-PÉREZ, Ana; SANTOS, Elena; ZILHÃO, João; ARSUAGA, Juan Luis (2018) - Taphonomic inferences about Middle Pleistocene hominins: The human cranium of Gruta da Aroeira (Portugal). American Journal of Physical Anthropology. 167:3, pp. 615-627.

STINER, Mary C; KUHN, Steven L; WEINER, Stephen; BAR-YOSEF, Ofer (1995) - Differential burning, recrystallization, and fragmentation of archaeological bone. Journal of Archaeological Science. 22:2, pp. 223-237.

TRINKAUS, Erik; MARKS, Anthony E; BRUGAL, Jean-Philip P; BAILEY, Shara E; RINK, W.Jack J; RICHTER, Daniel (2003) - Later Middle Pleistocene human remains from the Almonda Karstic System, Torres Novas, Portugal. Journal of human evolution. 45:3, pp. 219-226.

ZILHÃO, João; MAURÍCIO, João; SOUTO, Pedro (1993) Jazidas arqueológicas do sistema cársico da nascente do Almonda. Nova Augusta. 7, pp. 35-54. 

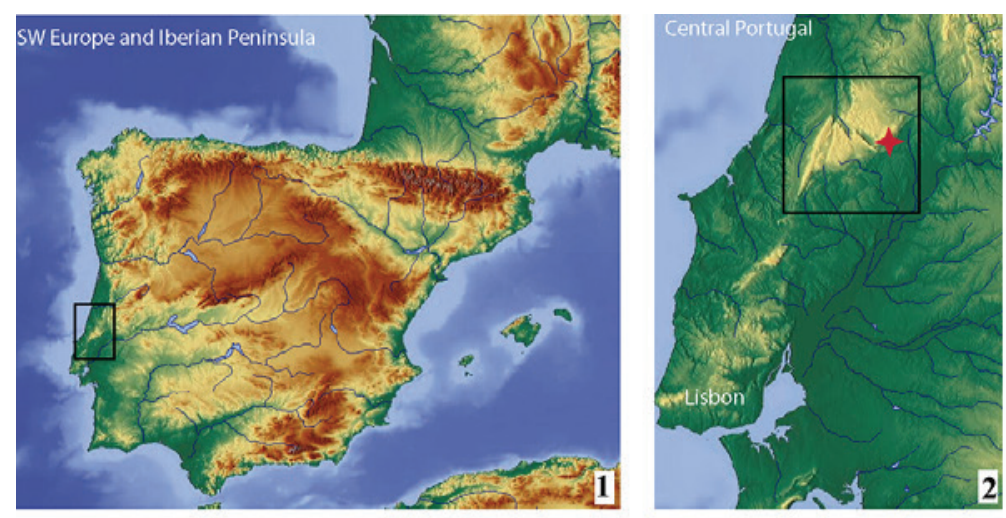

2

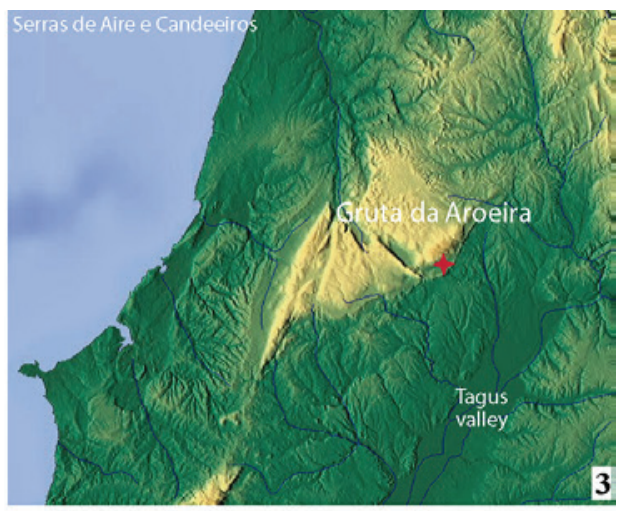

$55-6$
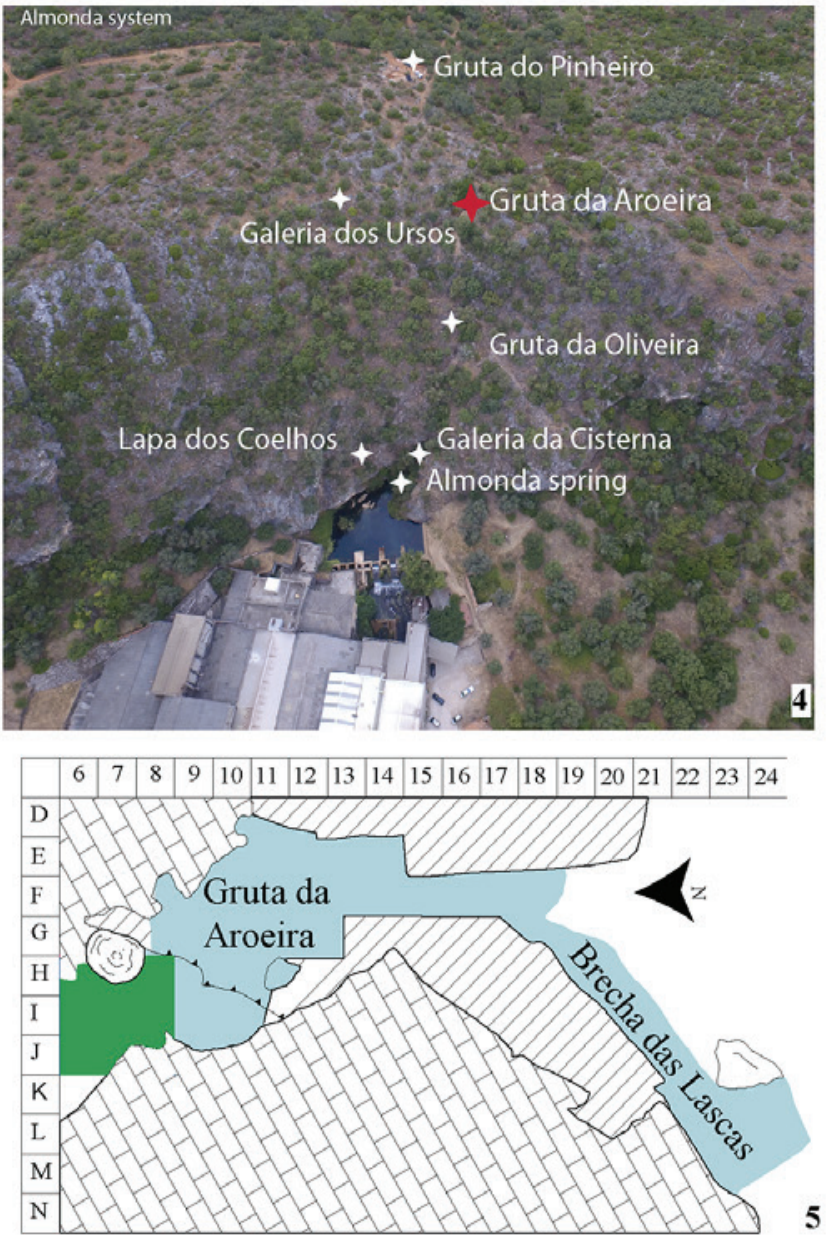

Legend

\begin{tabular}{|lc|}
\hline Cave wall / Bedrock & $\square$ 1998-2002 excavation \\
$\square$ Cave ceiling & $\square$ 2013-2017 excavation \\
Stalagmitic column & $\square$ Not excavated \\
- Layers - - Grid - Columm $\square$ Capping flowstone \\
\hline
\end{tabular}

4

5

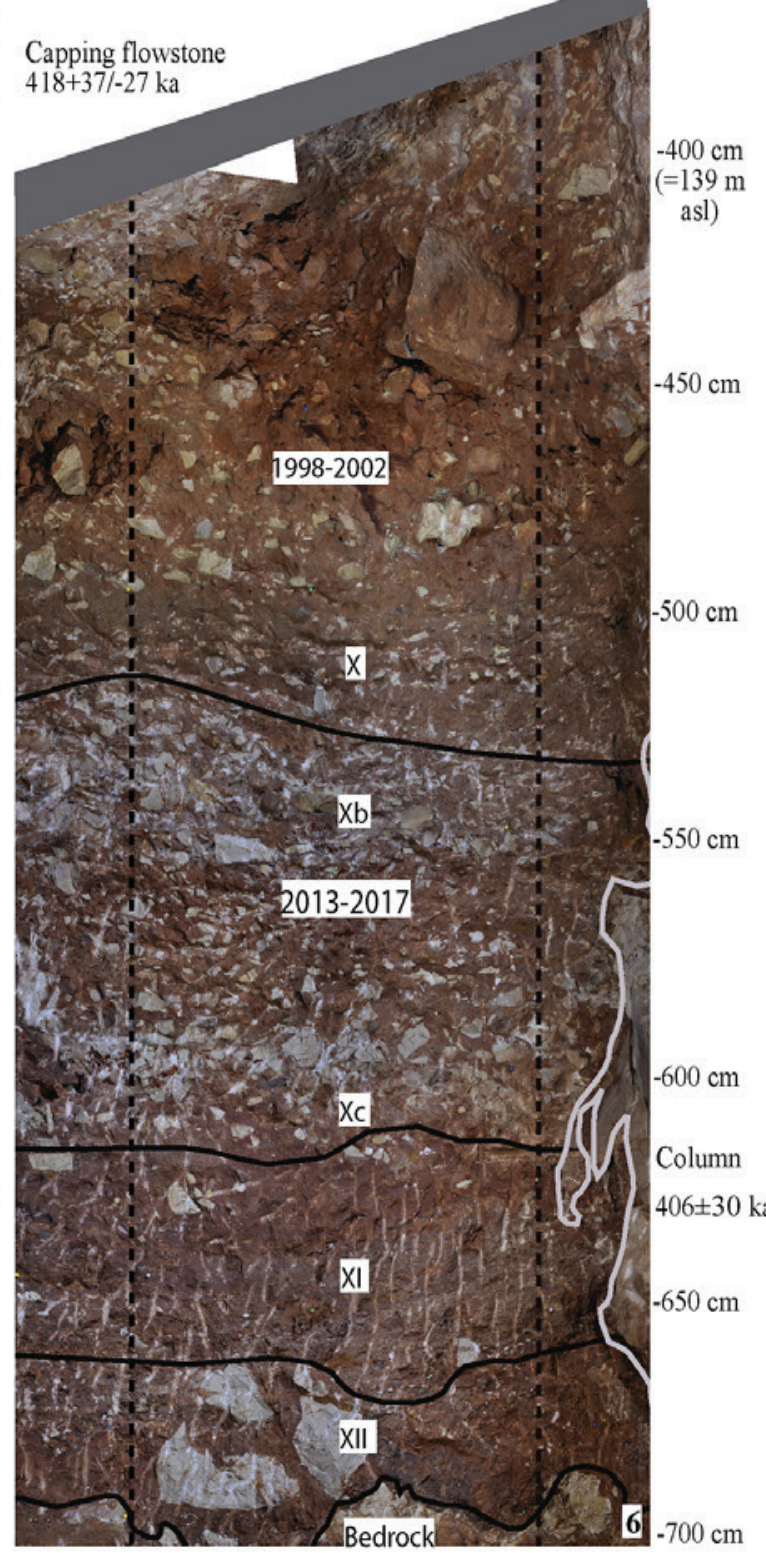

Figura 1- O sítio da Gruta da Aroeira. 1-3: Localização geográfica. 4: A escarpa do Almonda, com a posição da Gruta da Aroeira e a nascente do rio Almonda em primeiro plano. 5: Planta da Gruta da Aroeira eárea de escavação. 6: Corte estratigráfico principal. 


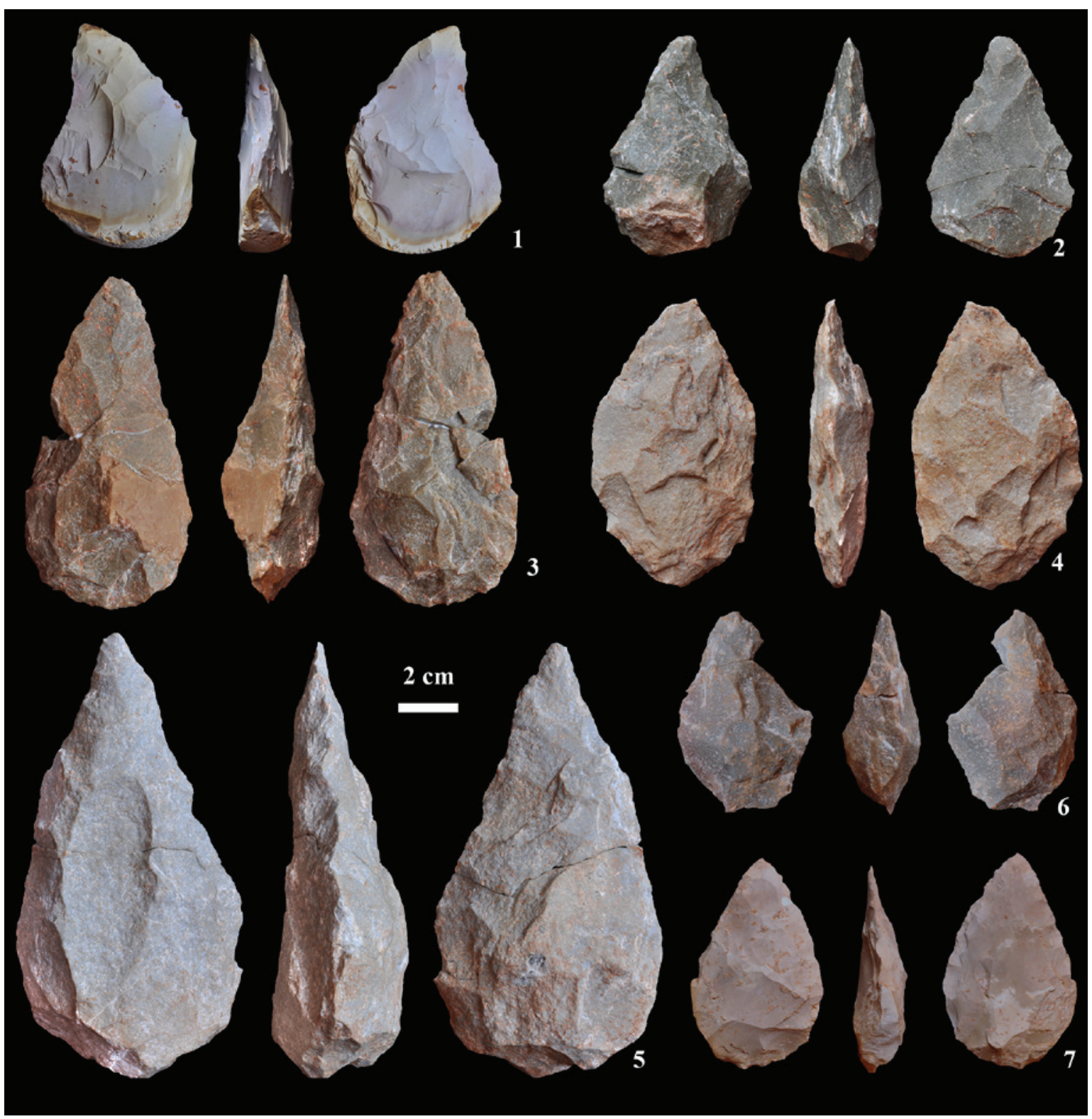

Figura 2 - Bifaces da camada X.

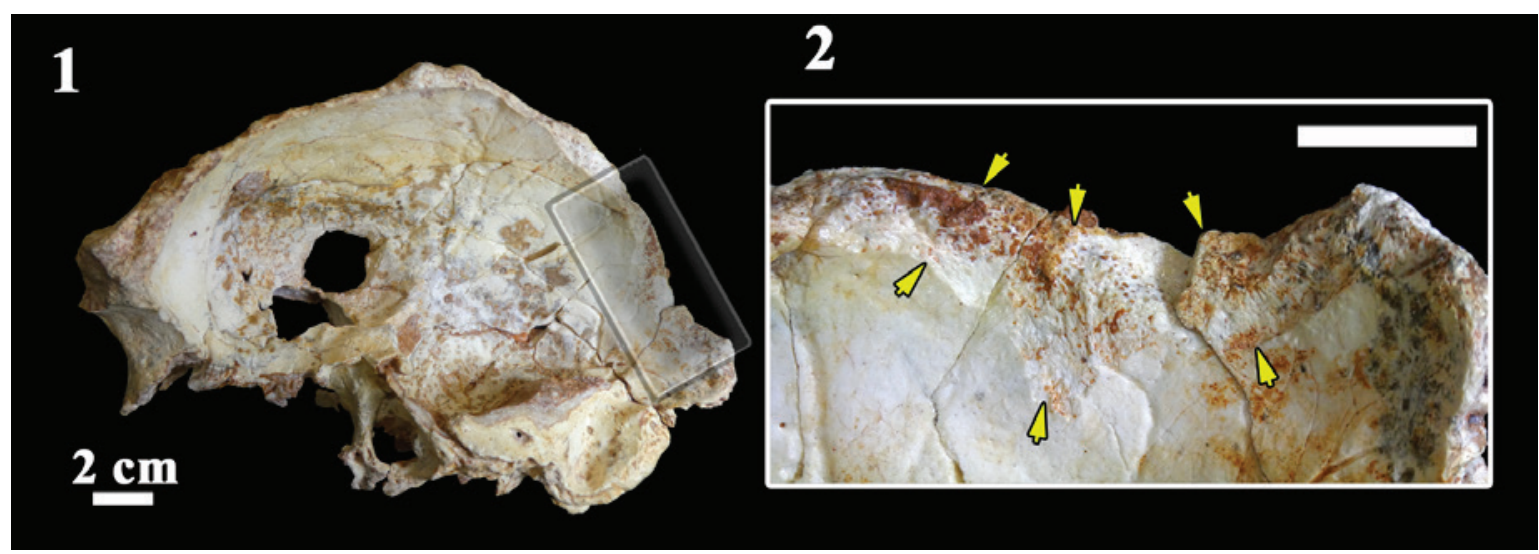

Figura 3 - Fractura perimortem da região posterior do osso parietal. 1: Vista endocraniana do fóssil. 2: Vista detalhada da fractura perimortem; as setas indicam descamações do córtex. 


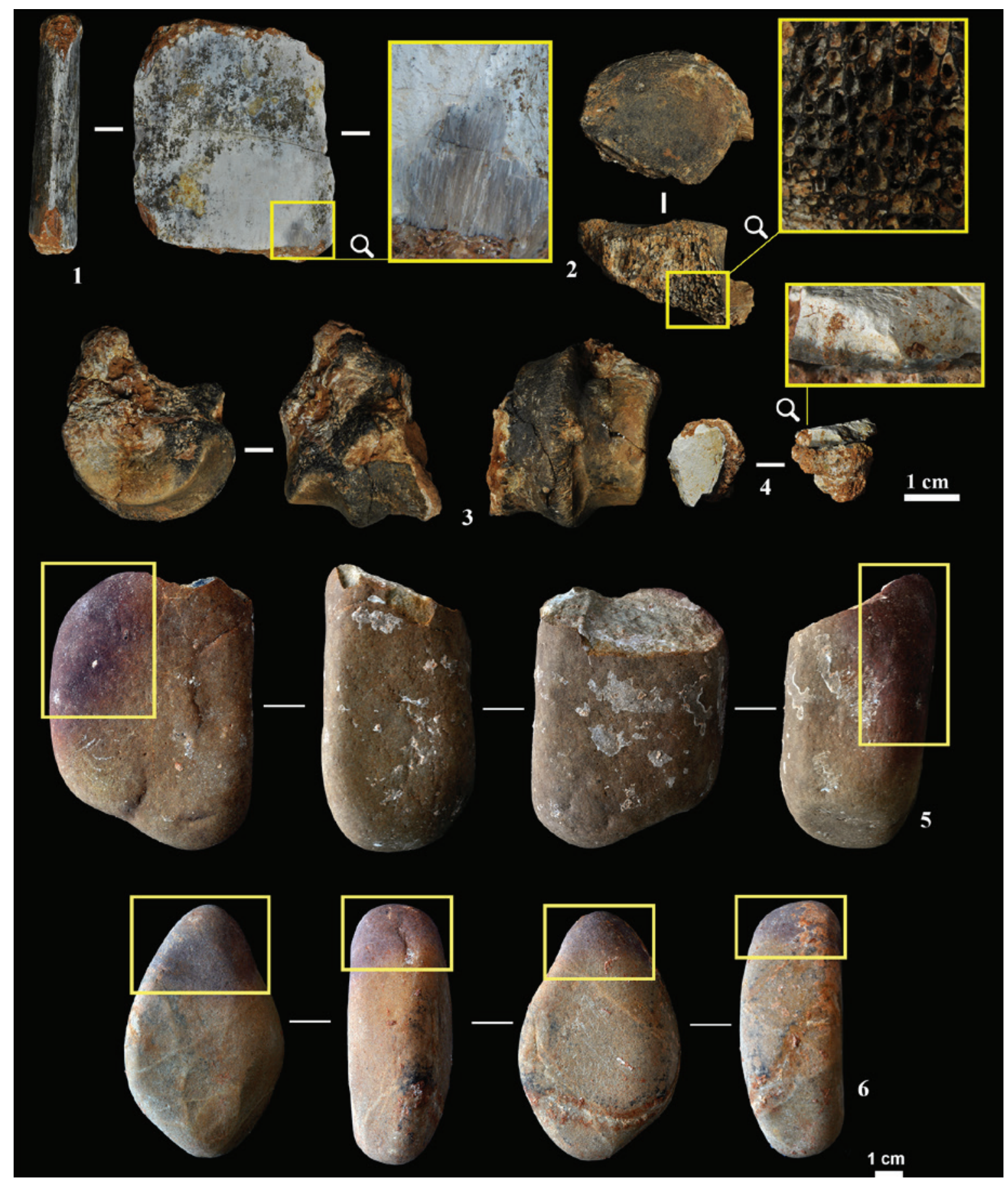

Figura 4-1-4. Ossos queimados. 5-6. Artefactos de quartzito com zonas avermelhadas e enegrecidas (assinaladas por rectângulos) possivelmente resultantes de alteração térmica. 



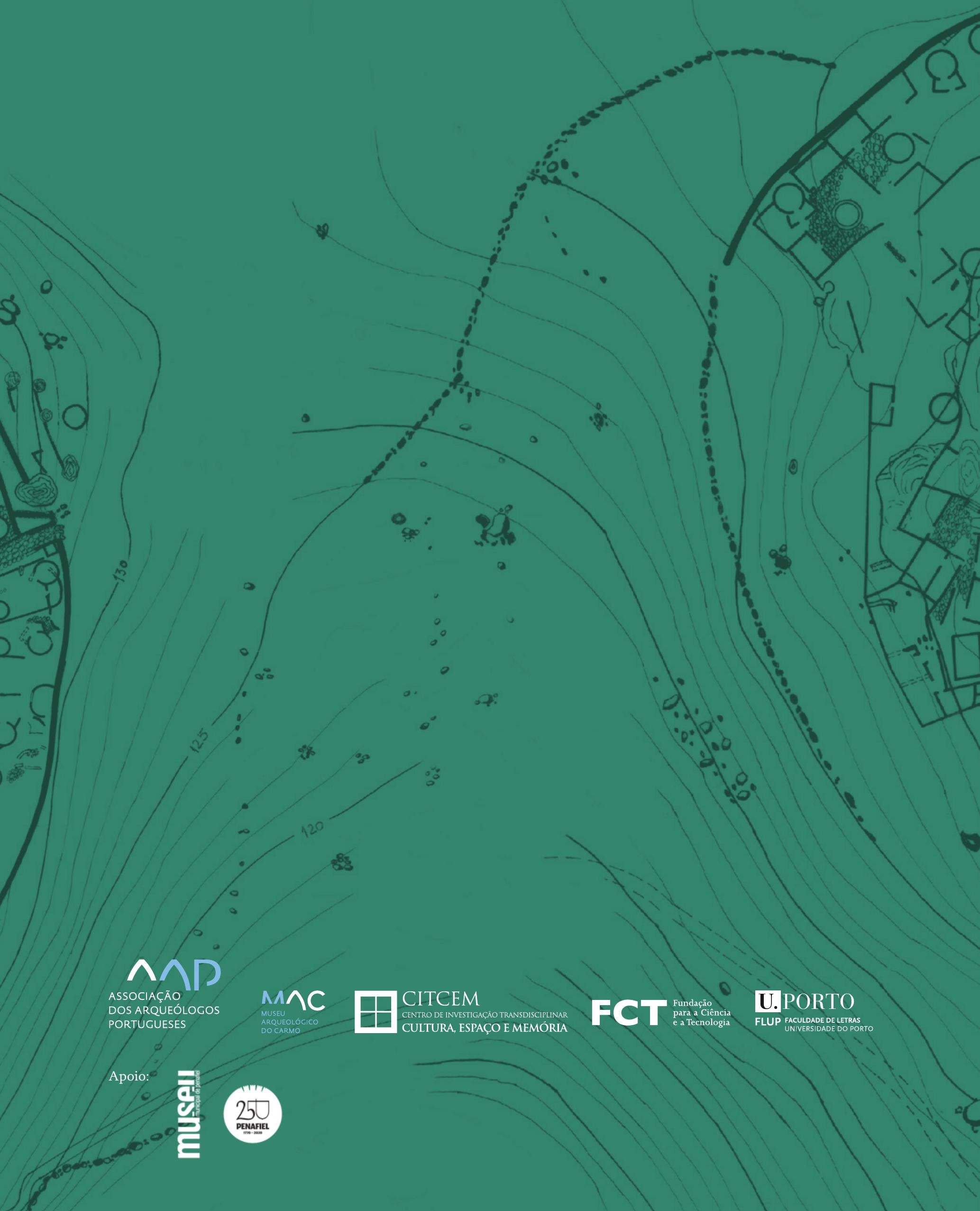

